\title{
Study of the Performance Incentive Mechanism for Management Staff in Higher Vocational Colleges
}

\author{
Hou Xijun, Yu Zhijun
}

Office of Personnel, Changzhou Institute of Textile Garment Technology, Changzhou, 213164, Jiangsu

Key words: higher vocational colleges, management team, performance incentive mechanism

\begin{abstract}
The reform and development of higher vocational colleges is the premise and guarantee for talents team construction and the management team construction is the key of guaranteeing the effective running and improving management efficiency of higher vocational colleges, besides, the performance incentive mechanism of management staff is the weak link of higher vocational college management work. This paper has expounded the significance, status quo and existing problems of performance incentive mechanism for management staff in higher vocational colleges, furthermore, on the basis of the concept of human resources management and by combining with the characteristics of higher vocational colleges management work as well as the actual problems appearing in the reform, it has put forward suggestions for perfecting performance incentive mechanism.

The personnel system reform in higher vocational colleges gradually stepped into the 'deep water area' and the reform effect directly affects the talents cultivation level and quality of higher vocational colleges. Performance incentive mechanism reform, as one of the core content of personnel system reform in higher vocational colleges, whether its system design is scientific and reasonable or not and whether it is suitable for the characteristics of higher vocational colleges or not, is directly related to the construction and stability of teachers team and management team. The performance incentive for management staff in higher vocational colleges is the weak link of college management, so on the basis of the present situation of performance incentive mechanism reform of higher vocational colleges, combined with the characteristics of higher vocational colleges and the practical problems appearing in the reform and through the design and innovation of performance incentive system of higher vocational colleges, it is necessary to stimulate human' s internal demand, effectively motivate the behavior of management teams, arouse the enthusiasm of management staff, promote the construction and stability of management teams and vigorously promote the continuous development of colleges' various undertakings.
\end{abstract}

\section{Introduction}

The employment system of higher vocational colleges has completed the transformation from 'identity management' to 'post management' and the opening of income distribution system reform has started. Effective performance incentive mechanism has become the key to the reform of the income distribution system and the performance incentive for management staff is still the weak link of colleges' performance incentive management. Therefore, the perfecting and innovation of 
performance incentive mechanism for management staff is the urgent request for income distribution system reform.

Speaking from the essence, the administrative management of higher vocational colleges is not controlling but limited management and service in place, however, influenced by the traditional management concept, the management staff regard themselves as the 'leader' " rather than

'server' , the performance incentive is bound to break the bondage of traditional concept and requires the managers to set up the concept of 'service' .

Management staff is the basic guarantee for the normal operation of colleges' each work. Management staff's overall quality and level directly affects the management efficiency of the college, besides, an effective performance incentive not only can stimulate the vitality of management team, but also plays an important role in strengthening the management team construction, improving management efficiency and promoting the reform and development of higher vocational colleges.

For the management staff, the performance incentive mechanism can effectively stimulate their internal behavior motivation and promote their work enthusiasm and efficiency.

Along with the refinement of management function division in higher vocational colleges, the requirements for the specialization level of management staff has become higher and higher, besides, higher requirement also has been put for the quality, ability and professional level of management staff, therefore, management staff is bearing the greater pressure, besides, the matching performance incentive mechanism has also played a vital role in increasing management staff's comprehensive quality and professional level. For the managers themselves, effective incentives can dig their internal potential and constantly improve their management level and management efficiency.

\section{Current Situation and Problems Analysis of Performance Incentive Mechanism for Management Staff in Higher Vocational Colleges}

Currently, the performance incentive mechanism for management staff in China's higher vocational colleges is not sound and the upward channel is not unimpeded, besides, it focuses on the performance evaluation rewards and the performance evaluation incentives measures are mainly reflected in the annual assessment or employment period assessment. The assessment content is the personal' s work conclusion or work report, which has the characteristics of great randomness and a link of conventional phrases and empty words, even that it exaggerate some performance and then causes the formalization of assessment, as a result, it does not have the effective positive incentives, but the negative incentives to some extent. Performance evaluation incentive mainly has the following problems.

Currently, the performance assessment of China' s higher vocational colleges mainly adopts the index quantification method through taking index decomposition of the work content of different positions and different levels of teaching, scientific research and management staff, establishing one standardized and quantitative assessment index and this method pursues the aim 'big and full' , and playing an effective incentive effect on some posts, however this assessment method can't 
reflect the characteristics of management post work. Meanwhile, in the assessment practice process, the management work still has the cross-cooperation behavior between departments and the working effect needs certain period and process to be fully revealed, which then causes the accuracy of performance evaluation management work in standardized and quantitative performance assessment standard to reduce greatly, as a result, it weakens the pertinence and effectiveness of management work assessment and then impact the work initiative, enthusiasm and creativity of management staff.

'Hidden' characteristics of management work and difficult embodiment of management staff' s performance level has led to the distortion of evaluation results.

The management work in higher vocational colleges is different from that the teaching and scientific research work is quantifiable, it has the 'hidden' characteristics, which is mainly reflected in the non-quantification, procedural property, temporary property and cross-department intersectionality. The above characteristics have led to that a lot of management work has certain hysteresis both for process and result, besides, it is difficult to be fully embodied in evaluation and the quantitative measure is difficult to achieve, which often needs the qualitative indicators to judge. At the same time, the temporariness and abruptness of management work often cause the work objective and plan be affected, besides, some work is of the cross-department intersection work and the inter-coordination and mutual support between the departments directly affects the work quality. The accurate delimitation of examination scope in the evaluation directly affects the evaluation results, otherwise, it will cause the distortion of the evaluation results.

The generalization of evaluation indicator content has weakened the effect of performance evaluation incentive mechanism.

The performance evaluation index system and content of many management staff in different position and levels from the higher vocational colleges are basically the same, which has no special evaluation index of classification and gradation. The generalization of evaluation content, not prominent performance evaluation keys, only paying attention to the common characteristics of management position work, ignoring the personalized requirements, only paying attention to the static evaluation and lack of the dynamic effects evaluation have led to the not strong incentive property of evaluation results.

At present, the personnel system reform in higher vocational colleges is getting constant advancement and deepening and it has stepped into the area of deep water, however, influenced by though of 'official position', the concept of different positions to corresponding rank is still strong, which has led to that the rising channel for management staff who are not in the leadership position is restricted and the rising channel of position level for the employees of non-leadership is not smooth, besides, it has led to that someone has been devoting themselves silently to one position for dozens of years, so as to it has seriously influenced the management staff's work enthusiasm and passion and suppressed the vigor and vitality of the management team, besides, the high level of management team and high efficiency of management level cannot be fully realized and some bad habits has begun to get spread, which to some extent, has inhibited the achievement of development goals of higher vocational colleges. 
Along with the constant changing of personnel management concept of higher vocational colleges, the modern human resources management concept has been widely accepted and it is the basis for leaders in higher vocational colleges to make relevant policies. Training incentive mechanism, as the important measure of promoting the development of teaching and administrative staff in higher vocational colleges, has played an important role in the construction of teaching staff in higher vocational colleges. However, the training incentive of higher vocational colleges mainly focuses on the front-line teachers and the training types and content are rich with broad radiating surface, which has really met the teachers' personal development needs. Management staff is mainly engaged in school' s daily management work and the transactional work is heavy, less chance of training and further education for management staff. The not sound management training incentive mechanism, especially the weak training and further education link for general management staff is unable to meet the personal development need and increase the level of business, which has seriously affected the increase of work level and management effectiveness.

\section{Analysis of the Needs Characteristics of Management Staff in Higher Vocation Colleges Based on the Maslow's Hierarchy of Needs}

Recently, with the further development of higher vocation colleges, the higher vocational colleges have continuously strengthened the construction and training force on talents team and also have increased the requirement for management staff' $s$ ability and quality unceasingly, so the management team have presented the new features, firstly, the trend of getting younger for management team is increasingly obvious; Secondly, the educational background structure of administrative staff has got constant promotion. The characteristics of getting younger and achieving higher degree of education for the management staff in higher vocational colleges has further illustrated that the management staff in higher vocational colleges have strong individual characteristics and self-awareness, which requires the higher vocational colleges use modern management concept, means and methods to take effective management on the management staff. According to Maslow's hierarchy of needs theory (pictured) and combined with the new change of higher vocational colleges management team, it has summarized the characteristics of the management staff in higher vocational colleges from the material needs, attribution needs, achievement needs, power needs and development needs, etc.

\section{$\begin{array}{lll}\text { Physiological safety needs } & \text { Emotion needs } & \text { Respect needs }\end{array}$ actualization needs}

As the show of new characteristics of getting younger and achieving higher degree of education for the management staff in higher vocational colleges, we have analyzed the differences of each management personnel' $s$ age, job title, duty, education background and valuesfrom the specific situation of management staff in higher vocational colleges, besides, their needs have the characteristics of individuality, differentiation and diversity. 
According to Maslow's hierarchy of needs theory, the needs of management staff in higher vocational colleges can be divided into lower-layer needs and higher layer needs and the lowerlayer needs mainly are physiological needs, security needs and social needs, in reality, it includes salary, bonus, social benefits etc. other material needs and the safety of physical, psychological and social needs. Higher-layer needs mainly is the emotion attribution needs, achievement and power needs, learning and development needs, etc., in reality, it mainly includes the recognition in work, honor rewards and position and rank promotion channels, training promotion etc.

The needs of management staff in higher vocational colleges is not static, with the constantly mature of management staff and the enrichment of experience, the needs is growing constantly, in general, management staff' s needs will increase along with the increase of age, title, educational background, position and rank to a higher level of development, which reflects the developmental characteristic.

To sum up in conclusion, the performance incentive mechanism for the management staff in higher vocational colleges not only needs to conform to the development goal and work content of the colleges, but also needs to take the the needs characteristics of management staff in higher vocation colleges into consideration, so that to meet its realistic needs, make the college development goal closely combine with the management staff' $s$ self-development, enhance the pertinence, effectiveness, long-term effect of performance incentive mechanism, beak through the bottleneck of personnel system reform of the higher vocational colleges and activate the vigor and vitality.

\section{Performance Incentive Mechanism Measures for Management Staff in Higher Vocational Colleges Under the Perspective of Needs Theory}

The personnel system reform of higher vocational colleges has stepped into deep-water area and the difficulties appear, the key for increasing management team level is to inspire management staff's work enthusiasm, work enthusiasm and initiative, so as to build a high level and high quality of management team. Discard the thought of 'official position' and further play down or break the leadership positions, besides, take in-depth implementation of staff-professional qualifications system, which is the core of activating the management team construction. Apart from holding the leadership position, actively promote the staff-professional qualification in non-leadership position system, provide more raising channels for the professional management staff who have good quality, high business level and strong management ability, meet the inner demand of different levels of management personnel, fully mobilize their enthusiasm and initiative and fully dig up the potential of management team, so that to provide institutional guarantee for building high quality and high level of management team and provide strong talents management guarantee for the development and expanding of colleges and the achievement of the goal.

How is the effect of performance assessment incentive playing? The key is that whether the assessment index system has truly reflected the characteristics of the post work for the people assessed or not, whether the assessment results can get the recognition of employers and employees or not and whether it can be more effective to play the positive role. This requires making and 
perfecting the assessment means and methods of performance assessment mechanism to be scientific and reasonable. The assessment content can fully reflect the management post responsibility and characteristics and the assessment results can fully arouse management staff' $\mathrm{s}$ enthusiasm.

Laying Emphasis on the 'Guidance Quality' and 'Three-dimensional Property' of Assessment Means and Methods

The performance assessment of higher vocational colleges should abandon the behavior of overdepending on 'system of rewards and penalties' in traditional personnel management concept, should update the concept, learn and apply the modern human resources management concept, regard the human as the potential 'resources' , embody the humanistic care in the performance assessment, respect fully management staff' s personality, accept their ability and potential. The fact has proved that connecting the performance assessment with rewards and penalties partially will discourage management staff' $s$ work enthusiasm and lead to the situation of only paying attention to the quantity of performance rewards but not the performance, even lead to that the goal of performance incentive has deviation and performance assessment effect is lightened. At the same time, the higher vocational colleges should learn and borrow enterprises' performance assessment means and methods, obtain the information with the help the superior, peer, subordinate and service object etc., build the all-around and multiple-dimension performance assessment process and enhance the transparency and comprehensiveness.

Due to the tacit characteristics, intersectionality and periodicity of management work, when e design the assessment content, we not only need to design reasonably the content easy for quantification and assessment, bu also need to pay attention to the design of the work content which has the characteristics of being unable to quantify, overlapping function and being unable to reflect the work performance. These achievements are easy to be ignored, however the role and effect is fundamental and some will have better working effect or result. At the same time, we should also pay attention to the assessment content differentiation of different levels and different positions, besides, the evaluation content of management post should not only have feathers in common, but also should reflect the differentiation of different post contents so that to make the performance assessment content do not become a mere formality.

The assessment result is only the reflection of a period of working and it cannot be used to measure the past andfuture of people who are assessed, so it is requested to give full play to the efficiency and pertinence of the assessment result besides, it is not allowed to decide the good or bad only according to the results and it is also not allowed to evaluate the past and future of management staff only in one time of assessment result. For the people with excellent assessment result, full recognition and reward should be given besides, give full play to their enthusiasm and advantage and promote the constant increase of their working ability and working effect. And for the people qualified or non-qualified, we should affirm their working performance and their efforts to work, and then provide employees with the opportunity of further training and improvement, besides, fully excavate their internal potential and make them grow and achieve improvement 
constantly, finally become the excellent management talents and enhance their sense of identity and belonging to the school.

Training improvement is the internal need for people to adapt to the society, adapt to the work and seek for personal long-term development. Building the management staff training and incentive mechanism in higher vocational colleges is to meet the internal needs of management staff, and the effective method promoting the increase of the management team's overall quality and level. Therefore, the management team should be same with the teachers in higher vocational colleges to accept the planned, targeted and professional theoretical training and management skills training, which can effectively promote the management staff to update knowledge, change ideas and improve ability quality, besides, it will be more helpful for the management staff to set up the modern human resource concept so as to adapt to and promote the constant development of vocational education.

The higher vocational colleges make management team construction planning, make the management team construction goal clear, establish different levels and different contents of training system, besides,combined with the management ability level, post responsibility and personal development needs of management staff, develop targeted training, meet the internal needs, sense of belonging and achievement of management staff.

Combined with the college management team construction planning, guide the management staff to make personal development planning so that to achieve the harmony and unify of personal development and college development, besides, colleges provide targeted training and through the training, meet their personal development needs, complete their post target and promote the achievement of college goals.

Strengthen the training assessment for management staff. Training, as an incentive, plays an important role in improving management staff' $s$ ability level, and the training assessment means and effect is the higher level of motivation, because it not only affects management staff' $s$ enthusiasm and psychological expectations in subsequent training process, but also affects the carrying out of subsequent training and the radiation of incentive effect. Grasping this link plays a crucial role in playing effectively the role of training incentive mechanism.

\section{Bibliography:}

[1] Liuyan, Linsen.defects and improvement thought of the performance assessment system for management staff in higher vocational colleges[J].marketing management,2012, （22） , 3334 page.

[2] Liu Qianhe.Study of the New Characteristics and Effective Incentive Ways for Administrative Staff in Higher Vocational Colleges[J].Journal of Taiyuan City Vocational College, 2013, (9) , 29-30 page.

[3] Zhao Jianmei.Analysis of the Teacher Incentive Problems and the Countermeasure in Higher Vocational Colleges[J], Journal of Tianjin Vocational Institute, 2010， （1），62-65 page.

[4] Hao Lianwang.Study of Management Team Construction in Higher Vocational Colleges Based 
on the Incentive Mechanism[J].Teaching Research, 2008， （4），330-332 page.

[5] Lin Xinghua, Xie Jiangtao. The Existing Problems of Performance Assessment System for Management Staff in Higher Vocational Colleges and The Perfection Measures[J]Journal of Southern Vocational Education,2011, （3）， 17-20 page.

[6] Zhao Wenye.Discussion of the Performance Assessment for the Administrative Staff in High Vocational Colleges[J].Science and Technology Information, 2009，（13），230-231 page. About the author: Hou Xijun(1982.3-), male, born in Changchun city, Jilin province, section chief, Office of Personnel, Changzhou Institute of Textile Garment Technology, assistant researcher, master, research direction: human resources management of higher vocational colleges; $\mathrm{Yu}$ Zhijun(1970.9-), male, born in Wangjiang city, Anhui province, director, Office of Personnel, Changzhou Institute of Textile Garment Technology, associate professor, research direction: human resources management of higher vocational colleges, economic management 